Review

\title{
Seasonal variations in vascular endothelial function and physical activity in men
}

\author{
Hiroto Honda ${ }^{1, *}$, Makoto Igaki ${ }^{2}$ \\ ${ }^{1}$ Faculty of Rehabilitation, Shijonawate Gakuen University, 574-0011 Daito, Japan \\ ${ }^{2}$ Department of Rehabilitation, Toyooka Hospital, 668-8501 Toyooka, Japan \\ *Correspondence: h-honda@un.shijonawate-gakuen.ac.jp (Hiroto Honda) \\ Submitted: 24 August 2021 Accepted: 19 October 2021 Available online: 26 October 2021 Published: 10 February 2022
}

\begin{abstract}
Vascular endothelial function, which plays an important independent role in the onset of cardiovascular disease, often changes seasonally, with functional deterioration generally occurring during the winter. Physical activity is necessary for preventing cardiovascular disease and all-cause mortality, as it improves vascular endothelial and metabolic function; however, the amount of physical activity an individual gets also varies with the seasons. Changes in physical activity may induce seasonal variations in vascular endothelial function, although this hypothesis remains unconfirmed. An individual's sex can also affect their vascular endothelial function, habitual physical activity, and hormonal and metabolic function. Men have a higher risk of cardiovascular disease compared to women; therefore, clarifying the impact of physical activity on vascular endothelial function and its seasonality is important for managing men's health. The purpose of this article is to review the association between seasonal variations in vascular endothelial function and physical activity in men.
\end{abstract}

Keywords: Vascular endothelial function; Physical activity; Seasonal variation; Hormonal function; Metabolic function

\section{Introduction}

Vascular dysfunction increases the risk of cardiovascular disease (CVD) [1]. Impairment of vascular endothelial function is an early pathophysiological process in the development of CVD, and it is the first step toward atherosclerosis [2]. Vascular endothelial cells, which affect vasodilation that is mediated by various endotheliumderived relaxing factors such as nitric oxide (NO), play an important role in inflammatory processes and anticoagulation [3]. Vascular endothelial function is affected by various factors, including metabolic function; for example, the serum cholesterol level is strongly related to impaired endothelial function and decreased NO bioavailability, which may induce functional arterial stiffening [4]. Flow-mediated dilation (FMD) is a non-invasive method that can be used to assess vascular function by quantifying endothelial function; therefore, the FMD value is considered an independent predictor of CVD $[5,6]$.

Sex can affect vascular endothelial function through the effect of sex hormones on agonists; sex hormones also induce differences in vascular endothelial function and the risk of CVD between men and women [7,8]. For men, testosterone is an important factor in the risk of both CVD and mortality, as it may have protective effects on the endothelium, arterial wall stiffness, and vascular reactivity $[9,10]$. Notably, the risk of CVD is higher in men than in premenopausal women $[11,12]$, but it is similar to that of postmenopausal women [13].

Vascular endothelial function can also be influenced by the changing seasons, with the risk of CVD being higher during the winter as vascular endothelial function worsens, especially in older individuals [14]. The seasonality of sex hormones may also influence seasonal variations in the risk of CVD [15-17]. Additionally, the amount of physical activity also changes seasonally for both sexes [18,19], and its reduction during the winter may contribute to the increased CVD risk.

The relationship between seasonal variations in vascular endothelial function and physical activity remains unclear. In a previous report, we discussed the influence of physical activity on seasonal variations in metabolic and vascular function; however, we did not examine sex differences [20]. Therefore, in this review, we will focus on the association between seasonal variations in vascular endothelial function and physical activity in men and discuss men's health as a target for preventing these variations.

\section{Seasonal variations in vascular endothelial function and its factors in men}

\subsection{Sex differences in vascular endothelial function}

FMD can be greater in women due to a higher shear rate when compared with similarly aged men [21]. A previous study showed that peak FMD value was significantly higher in women when compared with that of men [22]. Conversely, although aging changes the FMD value in both men and women, the change is more rapid in women than in aged men [23]. There may be sex differences in shear stress and vascular compliance [24].

\subsection{Seasonal variations in vascular endothelial function}

Various studies have investigated seasonal variations in vascular endothelial functions using FMD. A large popu- 
lation cross-sectional study $(n=2587,47 \%$ men, mean age: 61 years), which was analyzed from the Framingham Heart Study in different individuals across seasons, found that the FMD value (adjusted for the baseline diameter) changed seasonally; e.g., the highest and lowest values were observed during the summer (mean value: $3.01 \%$, from June 21 to September 20) and winter (mean value: $2.59 \%$, from December 21 to March 20), respectively [25]. Interestingly, sex (men vs. women) and age ( $\geq 60$ vs. $<60$ years) did not affect seasonal variations in the FMD value (numeric data comparing sex differences: unknown).

A previous study with a small sample size $(n=27$, $52 \%$ men, mean age: 60.4 years) in same individuals with type 2 diabetes, hypertension, and/or dyslipidemia prospectively examined whether the FMD value could vary across seasons, and the authors found that the FMD value for these individuals was lower during the cool season (from November to March) than it was during the warm season (from July to September) (mean value: $4.74 \%$ and $5.71 \%$, respectively) [26]. Although the detailed numeric data was not described in the report, the study showed that sex and age did not have an effect on seasonal variations in the FMD value.

A recent study in Japan ( $\mathrm{n}=1,067,171,58 \%$ men, mean age: 71.3 years) examined the association between diurnal outdoor temperature changes and CVD hospitalizations [27]. The results of this study showed the seasonality in the number of CVD hospitalizations through changes in diurnal outdoor temperature range which can affect vascular (including endothelial) function; however, no sex differences were observed.

Therefore, although vascular endothelial function deteriorations are observed during the winter in men, sex differences may not be associated with this seasonality.

\subsection{Influence of hormonal function}

Generally, men and women have different risks of CVD, due to the lack of physiological levels of estradiol in men of all ages [28], but this variability becomes nearly negligible with increased age [29]. Women's bodies undergo hormonal changes, especially during the early stages of menopause or later. A previous cross-sectional study (132 women, aged 22-70 years) revealed that vascular endothelial function starts to decrease during the early stages of menopause, and this deterioration is associated with reduced hormonal function, such as with prolonged estrogen deficiency [30]. Estradiol increases NO availability in both men and women, resulting in vasodilation, and testosterone contributes to a similar effect in men, whereas it induces reduced NO availability and impaired vasodilation in women [31].

Seasonal variations in serum hormone levels are observed in men. A study conducted over a period of $>9$ years (7491 men, mean age: 47.46 years) showed that the testosterone levels of the participants were higher during the summer than during the autumn, and the levels correlated with outdoor temperatures and daylight duration [16]. A cross-sectional study $(\mathrm{n}=3191,48 \%$ men, mean age: 60.1 years for men) also showed that total and free estradiol levels were higher in May and lower in October in men [15].

\subsection{Influence of metabolic function}

Metabolic function, including blood pressure, correlated with the risk of CVD and mortality [32,33]. Seasonal variations in metabolic function are observed when environmental factors (e.g., outdoor temperatures that affect blood circulation [25]) change. Exposure to cool air (low temperature) alters sympathetic nervous system activity and induces various endocrinological responses [34,35].

The systolic and diastolic blood pressures are independent determinants of vascular endothelial function [36]. Blood pressure varies with changes in the outdoor environments. Further, reduced vitamin D synthesis during winter can also increase blood pressure through reduced sun exposure and inhibition of the renin-angiotensin system [37]. A longitudinal study $(\mathrm{n}=8801,39 \%$ men, mean age: 74.3 years) also showed that low outdoor temperatures during the winter raised participants' blood pressures [38]. However, there was no difference in the seasonal blood pressure variation patterns between men and women. Thus, seasonal variations in vascular endothelial function that are induced by changes in blood pressure may lower FMD values during the cool season compared with the warm season without being influenced by sex [25].

Hyperglycemia and increased advanced glycation end-products also cause endothelial dysfunction (e.g., reduced endothelial-derived NO production) [39,40]. Low outdoor temperatures increase blood glucose concentrations [41,42], and the highest glycated hemoglobin (HbA1c) level may be observed during the winter because of increased insulin resistance due to increased body fat, which can be caused by increased plasma cortisol levels and tissue sensitivity to glucocorticoids during the winter [43], as well as increased blood glucose levels. In a study with a small sample size (11 men with diabetes, mean age: 60.4 years), the HbA1c level in men was the highest during the winter, and it was influenced by changes in body fat rather than body weight [44]. In a large population study (n $=285,705,98 \%$ men with diabetes, mean age: unknown), the participants' HbAlc levels were higher during the winter and lower during the summer; however, there was no difference in the seasonal HbAlc level changes between men and women [42].

Blood lipid profiles also change seasonally $[45,46]$. The deterioration of blood lipid profiles, such as the serum cholesterol level, induces impaired endothelial function and reduced NO bioavailability [4]. A previous study on adult workers (1202 men, mean age: 44 years) found that the high-density lipoprotein cholesterol (HDL-C) level was higher in men during the winter than during the summer 
[47]. Additionally, a cross-sectional study $(n=6894,42 \%$ men, mean age: 39.4 years for men) showed that the lowdensity lipoprotein cholesterol (LDL-C) level was higher in men during the winter than during the summer, whereas the LDL-C and HDL-C levels were consistent in women, regardless of the season [48]; thus, seasonal variations in blood lipid profiles may be greater in men than women.

In summary, seasonal variations in these metabolic functions may influence vascular endothelial function; however, although there are differences in the seasonal blood lipid profile patterns between men and women, no sex differences in the seasonal blood pressure and glucose level patterns may be observed.

\section{Influence of seasonal variations in physical activity on variations in vascular endothelial function in men}

\subsection{Effect of physical activity on vascular endothelial function}

Vascular endothelial function can be improved with regular physical activity [49]. Skeletal muscle contractions during physical activity increase local blood flow and cardiac output, which increase the shear stress on the vascular endothelium and NO production [50]. A metaanalysis of 16 prospective studies in which participants engaged in exercise training programs with durations of $\geq 8$ weeks showed that regular moderate-to-vigorous intensity aerobic training and combined aerobic and resistance training improved FMD values for individuals with type 2 diabetes, although the presence of diabetes may reduce endothelial function improvements [51]. Furthermore, a systematic review of 29 articles (27 studies that used either cross-sectional, prospective cohort, or randomized designs) showed that even short ( $\leq 10$ minutes) moderate-tovigorous physical activity improved resting blood pressure and reduced the risk of CVD as assessed by the Framingham Risk Score [52]. Therefore, increasing physical activity is an effective method for maintaining or improving vascular endothelial function, and it is important for reducing the risk of CVD and all-cause mortality [53,54].

A limited number of studies have examined whether there are sex differences in the response of vascular endothelial function to physical activity, including exercise. A previous study with a small sample size $(n=12,50 \%$ men, mean age: 58 years for men) showed that the FMD value for women tended to improve after 24 weeks of moderate intensity aerobic training, although not significantly [55]. Conversely, there was no change in the FMD value for men. Another intervention study $(\mathrm{n}=26,42 \%$ men, mean age: 63 years for men) showed that 8 weeks of moderateto-vigorous intensity aerobic training tended to increase the FMD value compared with the non-exercise condition, although not significantly; however, the change in the value in men was greater than that for postmenopausal women [56]. The authors also performed cross-sectional com- parisons between sedentary and endurance exercise-trained men and postmenopausal women $(n=167,63 \%$ men, mean age: 62 years for men) and found that the FMD value for exercise-trained men was greater than that of sedentary men, whereas there was no difference in the values between sedentary and exercise-trained women [56]. A previous review concluded that there were research gaps in sex differences associated with vascular adaptations to regular physical activity, including exercise [57]. Therefore, sex differences associated with vascular endothelial function changes based on physical activity remain unclear.

\subsection{Seasonal variations in physical activity}

It is noteworthy that the amount of physical activity undertaken by individuals may change seasonally due to lifestyles and climate conditions. Income [58], residence [59,60], and climate conditions (e.g., humidity, outdoor temperature $[61,62]$ ) can induce variations in habitual physical activity, based on the opportunities for regular participation in exercise, sports, and leisure-time activities [6365]. For both sexes, the amount of physical activity people engaged in during the winter is lower than it is during the summer $[18,19]$. A previous study $(n=2843,42 \%$ men, mean age: unknown) showed that the energy expenditure during leisure-time physical activities was significantly lower during the autumn and winter than it was during the spring and summer [64,65]. Another study ( $\mathrm{n}=41,49 \%$ men, mean age: 71 years for men) showed that a combination of outdoor temperature and $<1 \mathrm{~mm}$ /day of precipitation may influence physical activity and change the number of daily steps an individual takes, with the highest number of steps occurring at a temperature of approximately $17^{\circ} \mathrm{C}$ [62]. Additionally, seasonal variations in physical activity are observed in healthy individuals, as well as those with diseases (e.g., heart failure, chronic obstructive pulmonary disease $[66,67])$.

The type of physical activity may exhibit different seasonal change patterns. A cohort study on adults aged $\geq 50$ years ( $n=1166,56 \%$ men, mean age: unknown) showed that engagement in light and moderate-to-vigorous physical activities was higher during the summer than during the winter among middle-aged (50-64 years) and youngelderly (65-74 years) adults, whereas seasonal variations in physical activity were not observed among old-elderly ( $\geq 75$ years) adults [68]. Furthermore, sedentary behavior did not show a seasonal pattern among any of the age groups. Conversely, a systematic review and meta-analysis of 17 studies (healthy adults aged 18-65 years) revealed that the light and moderate-to-vigorous physical activity rates were the highest during the summer, whereas the rate of sedentary behavior was the highest during the winter [69].

There are sex differences in physical activity, and they favor men [58], whereas sedentary behavior may not be affected by sex [70]. A large population cohort study (n $=31,546,70 \%$ men, $\geq 55$ years of age, mean age: un- 
known) showed that less physical activity was observed among women compared to men (exercise $\geq 2$ times/week: $68.9 \%$ of men vs. $56.6 \%$ of women), although sex differences in physical activity did not affect the incidence of acute myocardial infarction [11]. A previous study with a small sample size $(n=24,38 \%$ men, mean age: 26 years for men) showed that physical activity during the summer was greater than during the winter for both sexes, although the difference between the seasons was higher for men than women [71]. Conversely, the aforementioned study showed no sex differences in the seasonality of physical activity [68]. Another study on adults with heart failure ( $\mathrm{n}=$ $87,71 \%$ men, mean age: 70 years) showed that there were no differences in sex or age between the proportions of individuals whose physical activity levels decreased during the winter and those whose levels stayed the same or increased compared with the summer [67]. Further, a previous longitudinal study $(\mathrm{n}=95,43 \%$ men, mean age: 71.2 years for men) showed the seasonal change patterns in physical activity (daily step count and daily physical activity durations $<3$ and $>3$ metabolic equivalents) were not different based on sex or age [72]. Therefore, it remains unclear whether sex and/or age affects seasonal variations in physical activity.

\subsection{Association between seasonal variations in physical activity and vascular endothelial function}

It is unclear whether seasonal variations in physical activity affect variations in vascular endothelial function. The two previous studies that evaluated seasonal variations in the FMD value were performed without accounting for the individuals' physical activities $[25,26]$. As previously mentioned, increasing physical activity can improve vascular endothelial function as well as metabolic function, and it is possible that seasonal variations in these functions may decrease if individuals maintain their physical activity levels throughout the year. Few studies have investigated the effect of exercise or promoting physical activity on the suppression of seasonal variations in vascular endothelial function. A previous study on children $(n=116$, $40 \%$ boys, mean age: 10.4 years for boys) showed that seasonal variations in the FMD value correlated with those in vigorous-intensity physical activity, although not in lowand moderate-intensity physical activities [73]; remarkably, when the authors analyzed the data according to sex differences, this correlation was only observed for boys. Another study on adults with type 2 diabetes, hypertension, and/or dyslipidemia $(n=31,39 \%$ men, mean age: 66.3 years) showed that maintaining exercise habits by going to a gym could not diminish the deterioration of the FMD value and blood pressure during the winter, although it could suppress seasonal variations in some metabolic functions (e.g., blood lipid profiles) [74]. However, there is a lack of evidence regarding the association between seasonal variations in physical activity and vascular endothelial function for various age groups; naturally, it is unclear whether sex affects the association.

\subsection{How do men manage their physical activity to prevent seasonal variations in vascular endothelial function?}

As discussed above, there is no clear evidence that promoting physical activity throughout the year suppresses seasonal variations in vascular endothelial function in men. Furthermore, it remains unclear whether changes in other factors, such as sex hormones and metabolic function, due to physical activity can lead to a positive effect on preventing vascular endothelial function seasonality.

For men, physical activity acutely increases total and free testosterone levels [75,76]. For example, testosterone concentrations in men are acutely elevated following highintensity exercise, especially heavy resistance exercise [77, 78]. Additionally, long-term (10 weeks) resistance exercise may lead to increased post-exercise total testosterone concentrations [79]. In contrast, the chronic effect of aerobic exercise on testosterone levels remains unclear [80,81]. Further, a cross-sectional study $(\mathrm{n}=3507,44 \%$ men, mean age: 60 years for men) showed that physical activity levels (moderate and high-intensity activities) for men were negatively associated with the level of follicle-stimulating hormone, which regulates the testosterone level [82]. The testosterone response to resistance exercise may increase with age, as shown by the observation that an acute increase in testosterone in response to resistance exercise occurred in college-aged men, but not in boys and high school-aged men $[83,84]$. Conversely, although the testosterone levels for middle-aged and older men increased acutely after a session of resistance exercise, the volume increase was smaller than it was for younger adult men [85-87]. The observed increases may have been induced by increased concentrations of sex hormone-binding globulin, which is the primary binding protein for testosterone [88]; notably, sex hormone-binding globulin is affected by aging [89]. Therefore, although it remains unclear whether promoting physical activity can decrease seasonal variations in vascular endothelial function through changes in sex hormones, performing regular high-intensity resistance exercise throughout the year may suppress vascular endothelial function deterioration in men, especially in younger adult men.

Poor blood glucose control during the winter is caused by decreased physical activity in individuals with type 2 diabetes [90]. Seasonal deterioration of body weight and blood lipid profiles in overweight and obese individuals may be observed due to reduced physical activity during the winter compared to other seasons [91,92]. However, it remains unclear whether promoting physical activity, especially during the winter (e.g., during Christmas holidays), can protect against unfavorable metabolic function changes. A previous study (38 men, mean age: 57 years) showed that in men, exercise can suppress deterioration of various metabolic parameters, such as body weight, blood 
pressure, the homeostasis model assessment of insulin resistance, and the low-density lipoprotein cholesterol level [93]. Conversely, another study with a high proportion of women $(\mathrm{n}=148,32 \%$ men, mean age: 32.3 years for men) showed that holiday-related body weight and fat gain cannot be prevented by exercise [94]. Therefore, although it is not clear evidence, promoting physical activity during the winter may reduce deterioration of metabolic function in men. A recent review showed that carbohydrate oxidation during moderate aerobic exercise was greater in sedentary men compared with women, while lipid oxidation was lower in men [95]. Additionally, men have more increased cardiovascular and metabolic counterregulatory responses (e.g., systolic blood pressure and carbohydrate oxidation) during moderate-intensity aerobic exercise than women [96]. However, decreased muscle mass and strength and increased adiposity through reduced physical capacity are induced by aging [97-99]; thus, these changes that occur in older individuals can cause less energy consumption during the same relative intensity exercise compared with younger individuals. In summary, promoting physical activity, including exercise, may be able to suppress seasonal variations in metabolic function in men, especially in younger men.

Based on this information, additional prospective studies are needed to confirm the hypothesis that increasing physical activity during the winter or maintaining it throughout the year can directly or indirectly suppress seasonal variations in vascular endothelial function in men by improving hormonal and/or metabolic function.

\section{Conclusions}

Various factors, such as climate conditions, affect an individual's physical activity level and vascular endothelial function. However, there is no clear evidence that seasonal variations in physical activity induce variations in endothelial function in men. Clarifying the influence of physical activity on the seasonality of endothelial function may be necessary to maintain men's health, especially to protect against functional deterioration during the cool season. Further cohort research focusing on the association between seasonal variations in physical activity and vascular endothelial function in men is needed.

\section{Abbreviations}

CVD, cardiovascular disease; NO, nitric oxide; FMD, flow-mediated dilation; HbAlc, glycated hemoglobin; HDL-C, high-density lipoprotein cholesterol; LDL-C, lowdensity lipoprotein cholesterol.

\section{Author contributions}

$\mathrm{HH}$ and MI conceived of the presented idea and wrote the paper. All authors read and approved the final manuscript.

\section{Ethics approval and consent to participate}

Not applicable.

\section{Acknowledgment}

Thanks to all the peer reviewers for their opinions and suggestions.

\section{Funding}

This research received no external funding.

\section{Conflict of interest}

The authors declare no conflict of interest.

\section{References}

[1] Lerman A, Zeiher AM. Endothelial function: cardiac events. Circulation. 2005; 111: 363-368.

[2] Neunteufl T, Heher S, Katzenschlager R, Wolfl G, Kostner K, Maurer $\mathrm{G}$, et al. Late prognostic value of flow-mediated dilation in the brachial artery of patients with chest pain. American Journal of Cardiology. 2000; 86: 207-210.

[3] Vanhoutte PM, Shimokawa H, Feletou M, Tang EH. Endothelial dysfunction and vascular disease - a 30th anniversary update. Acta Physiologica. 2017; 219: 22-96.

[4] Wilkinson IB, Cockcroft JR. Cholesterol, endothelial function and cardiovascular disease. Current Opinion in Lipidology. 1998; 9: 237-242.

[5] Gokce N, Keaney JF Jr., Hunter LM, Watkins MT, Menzoian JO, Vita JA. Risk stratification for postoperative cardiovascular events via noninvasive assessment of endothelial function: a prospective study. Circulation. 2002; 105: 1567-1572.

[6] Yeboah J, Folsom AR, Burke GL, Johnson C, Polak JF, Post W, et al. Predictive value of brachial flow-mediated dilation for incident cardiovascular events in a population-based study: the multi-ethnic study of atherosclerosis. Circulation. 2009; 120: 502-509.

[7] Reckelhoff JF, Fortepiani LA. Novel mechanisms responsible for postmenopausal hypertension. Hypertension. 2004; 43: 918 923.

[8] Rosano GM, Sheiban I, Massaro R, Pagnotta P, Marazzi G, Vitale $\mathrm{C}$, et al. Low testosterone levels are associated with coronary artery disease in male patients with angina. International Journal of Impotence Research. 2007; 19: 176-182.

[9] Dockery F, Bulpitt CJ, Donaldson M, Fernandez S, Rajkumar C. The relationship between androgens and arterial stiffness in older men. Journal of the American Geriatrics Society. 2003; 51: $1627-1632$.

[10] Pearson LJ, Yandle TG, Nicholls MG, Evans JJ. Regulation of endothelin-1 release from human endothelial cells by sex steroids and angiotensin-II. Peptides. 2008; 29: 1057-1061.

[11] Kappert K, Bohm M, Schmieder R, Schumacher H, Teo K, Yusuf $\mathrm{S}$, et al. Impact of sex on cardiovascular outcome in patients at high cardiovascular risk: analysis of the Telmisartan Randomized Assessment Study in ACE-Intolerant Subjects With Cardiovascular Disease (TRANSCEND) and the Ongoing Telmisartan Alone and in Combination With Ramipril Global End Point Trial (ONTARGET). Circulation. 2012; 126: 934-941.

[12] Yang XP, Reckelhoff JF. Estrogen, hormonal replacement therapy and cardiovascular disease. Current Opinion in Nephrology and Hypertension. 2011; 20: 133-138.

[13] Yang XC, Jing TY, Resnick LM, Phillips GB. Relation of hemostatic risk factors to other risk factors for coronary heart disease 
and to sex hormones in men. Arteriosclerosis and Thrombosis. 1993; 13: 467-471.

[14] Fares A. Winter cardiovascular diseases phenomenon. North American Journal of Medical Sciences. 2013; 5: 266-279.

[15] Bjornerem A, Straume B, Oian P, Berntsen GK. Seasonal variation of estradiol, follicle stimulating hormone, and dehydroepiandrosterone sulfate in women and men. Journal of Clinical Endocrinology and Metabolism. 2006; 91: 3798-3802.

[16] Santi D, Spaggiari G, Granata ARM, Setti M, Tagliavini S, Trenti T, et al. Seasonal Changes of Serum Gonadotropins and Testosterone in Men Revealed by a Large Data Set of RealWorld Observations Over Nine Years. Frontiers in Endocrinology. 2019; 10: 914

[17] Smith RP, Coward RM, Kovac JR, Lipshultz LI. The evidence for seasonal variations of testosterone in men. Maturitas. 2013; 74: 208-212.

[18] Dannenberg AL, Keller JB, Wilson PW, Castelli WP. Leisure time physical activity in the Framingham Offspring Study. Description, seasonal variation, and risk factor correlates. American Journal of Epidemiology. 1989; 129: 76-88.

[19] Shephard RJ, Aoyagi Y. Seasonal variations in physical activity and implications for human health. European Journal of Applied Physiology. 2009; 107: 251-271.

[20] Honda H, Igaki M, Komatsu M, Tanaka S. Association between Physical Activity and Seasonal Variations in Metabolic and Vascular Function in Adults. Endocrines. 2021; 2: 150-159.

[21] Skaug EA, Aspenes ST, Oldervoll L, Morkedal B, Vatten L, Wisloff $U$, et al. Age and gender differences of endothelial function in 4739 healthy adults: the HUNT3 Fitness Study. European Journal of Preventive Cardiology. 2013; 20: 531-540.

[22] Dengel DR, Jacobs DR, Steinberger J, Moran AM, Sinaiko AR. Gender differences in vascular function and insulin sensitivity in young adults. Clinical Science. 2011; 120: 153-160.

[23] Sarabi M, Millgard J, Lind L. Effects of age, gender and metabolic factors on endothelium-dependent vasodilation: a population-based study. Journal of Internal Medicine. 1999; 246: 265-274.

[24] Pabbidi MR, Kuppusamy M, Didion SP, Sanapureddy P, Reed JT, Sontakke SP. Sex differences in the vascular function and related mechanisms: role of $17 \beta$-estradiol. American Journal of Physiology: Heart and Circulatory Physiology. 2018; 315: H1499-H1518.

[25] Widlansky ME, Vita JA, Keyes MJ, Larson MG, Hamburg NM, Levy D, et al. Relation of season and temperature to endothelium-dependent flow-mediated vasodilation in subjects without clinical evidence of cardiovascular disease (from the Framingham Heart Study). American Journal of Cardiology. 2007; 100: 518-523

[26] Iwata M, Miyashita Y, Kumagai H. Seasonal variation of endothelium-dependent flow-mediated vasodilation measured in the same subjects. American Journal of Cardiovascular Disease. 2012; 2: 111-115.

[27] Yoneyama K, Nakai M, Higuma T, Teramoto K, Watanabe M, Kaihara T, et al. Weather temperature and the incidence of hospitalization for cardiovascular diseases in an aging society. Scientific Reports. 2021; 11: 10863.

[28] Ndzie Noah ML, Adzika GK, Mprah R, Adekunle AO, AduAmankwaah J, Sun H. Sex-Gender Disparities in Cardiovascular Diseases: The Effects of Estrogen on eNOS, Lipid Profile, and NFATs During Catecholamine Stress. Frontiers in Cardiovascular Medicine. 2021; 8: 639946.

[29] Papakonstantinou NA, Stamou MI, Baikoussis NG, Goudevenos J, Apostolakis E. Sex differentiation with regard to coronary artery disease. Journal of Cardiology. 2013; 62: 4-11.

[30] Moreau KL, Hildreth KL, Meditz AL, Deane KD, Kohrt WM. Endothelial function is impaired across the stages of the menopause transition in healthy women. Journal of Clinical Endocrinology and Metabolism. 2012; 97: 4692-4700.

[31] Stanhewicz AE, Wenner MM, Stachenfeld NS. Sex differences in endothelial function important to vascular health and overall cardiovascular disease risk across the lifespan. American Journal of Physiology: Heart and Circulatory Physiology. 2018; 315 H1569-H1588.

[32] Arnett DK, Blumenthal RS, Albert MA, Buroker AB, Goldberger ZD, Hahn EJ, et al. 2019 ACC/AHA Guideline on the Primary Prevention of Cardiovascular Disease: Executive Summary: A Report of the American College of Cardiology/American Heart Association Task Force on Clinical Practice Guidelines. Circulation. 2019; 140: e563-e595.

[33] Williams B, Mancia G, Spiering W, Agabiti Rosei E, Azizi M, Burnier M, et al. $2018 \mathrm{ESC} / \mathrm{ESH}$ Guidelines for the management of arterial hypertension. European Heart Journal. 2018; 39: 3021-3104.

[34] Makinen TM, Mantysaari M, Paakkonen T, Jokelainen J, Palinkas LA, Hassi J, et al. Autonomic nervous function during whole-body cold exposure before and after cold acclimation. Aviation Space and Environmental Medicine. 2008; 79: 875882.

[35] Mourot L, Bouhaddi M, Regnard J. Effects of the cold pressor test on cardiac autonomic control in normal subjects. Physiological Research. 2009; 58: 83-91.

[36] Maruhashi T, Soga J, Fujimura N, Idei N, Mikami S, Iwamoto $\mathrm{Y}$, et al. Relationship between flow-mediated vasodilation and cardiovascular risk factors in a large community-based study. Heart. 2013; 99: 1837-1842.

[37] Cuspidi C, Ochoa JE, Parati G. Seasonal variations in blood pressure: a complex phenomenon. Journal of Hypertension. 2012; 30: 1315-1320.

[38] Alperovitch A, Lacombe JM, Hanon O, Dartigues JF, Ritchie K, Ducimetiere $\mathrm{P}$, et al. Relationship between blood pressure and outdoor temperature in a large sample of elderly individuals: the Three-City study. Archives of Internal Medicine. 2009; 169: 7580 .

[39] Tan KC, Chow WS, Ai VH, Metz C, Bucala R, Lam KS. Advanced glycation end products and endothelial dysfunction in type 2 diabetes. Diabetes Care. 2002; 25: 1055-1059.

[40] Williams SB, Goldfine AB, Timimi FK, Ting HH, Roddy MA, Simonson DC, et al. Acute hyperglycemia attenuates endothelium-dependent vasodilation in humans in vivo. Circulation. 1998; 97: 1695-1701.

[41] Kershenbaum A, Kershenbaum A, Tarabeia J, Stein N, Lavi I, Rennert G. Unraveling seasonality in population averages: an examination of seasonal variation in glucose levels in diabetes patients using a large population-based data set. Chronobiology International. 2011; 28: 352-360.

[42] Tseng CL, Brimacombe M, Xie M, Rajan M, Wang H, Kolassa $\mathrm{J}$, et al. Seasonal patterns in monthly hemoglobin A1c values. American Journal of Epidemiology. 2005; 161: 565-574.

[43] Walker BR, Best R, Noon JP, Watt GC, Webb DJ. Seasonal variation in glucocorticoid activity in healthy men. Journal of Clinical Endocrinology and Metabolism. 1997; 82: 4015-4019.

[44] Sohmiya M, Kanazawa I, Kato Y. Seasonal changes in body composition and blood $\mathrm{HbA} 1 \mathrm{c}$ levels without weight change in male patients with type 2 diabetes treated with insulin. Diabetes Care. 2004; 27: 1238-1239.

[45] Gordon DJ, Trost DC, Hyde J, Whaley FS, Hannan PJ, Jacobs DR Jr., et al. Seasonal cholesterol cycles: the Lipid Research Clinics Coronary Primary Prevention Trial placebo group. Circulation. 1987; 76: 1224-1231.

[46] Grimes DS, Hindle E, Dyer T. Sunlight, cholesterol and coronary heart disease. QJM: An International Journal of Medicine. 1996; 89: 579-589. 
[47] Kamezaki F, Sonoda S, Tomotsune Y, Yunaka H, Otsuji Y. Seasonal variation in metabolic syndrome prevalence. Hypertension Research. 2010; 33: 568-572.

[48] Hadaegh F, Harati H, Zabetian A, Azizi F. Seasonal variability of serum lipids in adults: Tehran Lipid and Glucose Study. Medical Journal of Malaysia. 2006; 61: 332-338.

[49] Ignarro LJ. Nitric oxide as a unique signaling molecule in the vascular system: a historical overview. Journal of Physiology and Pharmacology. 2002; 53: 503-514.

[50] Ando J, Yamamoto K. Effects of shear stress and stretch on endothelial function. Antioxid Redox Signal. 2011; 15: 1389 1403.

[51] Qiu S, Cai X, Yin H, Sun Z, Zugel M, Steinacker JM, et al. Exercise training and endothelial function in patients with type 2 diabetes: a meta-analysis. Cardiovascular Diabetology. 2018; 17: 64.

[52] Jakicic JM, Kraus WE, Powell KE, Campbell WW, Janz KF, Troiano RP, et al. Association between Bout Duration of Physical Activity and Health: Systematic Review. Medicine \& Science in Sports \& Exercise. 2019; 51: 1213-1219.

[53] Higueras-Fresnillo S, Cabanas-Sanchez V, Lopez-Garcia E, Esteban-Cornejo I, Banegas JR, Sadarangani KP, et al. Physical Activity and Association Between Frailty and All-Cause and Cardiovascular Mortality in Older Adults: Population-Based Prospective Cohort Study. Journal of the American Geriatrics Society. 2018; 66: 2097-2103.

[54] Kodama S, Tanaka S, Heianza Y, Fujihara K, Horikawa C, Shimano $\mathrm{H}$, et al. Association between physical activity and risk of all-cause mortality and cardiovascular disease in patients with diabetes: a meta-analysis. Diabetes Care. 2013; 36: 471-479.

[55] Black MA, Cable NT, Thijssen DH, Green DJ. Impact of age, sex, and exercise on brachial artery flow-mediated dilatation. American Journal of Physiology: Heart and Circulatory Physiology. 2009; 297: H1109-1116.

[56] Pierce GL, Eskurza I, Walker AE, Fay TN, Seals DR. Sexspecific effects of habitual aerobic exercise on brachial artery flow-mediated dilation in middle-aged and older adults. Clinical Science. 2011; 120: 13-23.

[57] Seals DR, Nagy EE, Moreau KL. Aerobic exercise training and vascular function with ageing in healthy men and women. Journal of Physiology. 2019; 597: 4901-4914.

[58] Guthold R, Stevens GA, Riley LM, Bull FC. Worldwide trends in insufficient physical activity from 2001 to 2016: a pooled analysis of 358 population-based surveys with 1.9 million participants. The Lancet Global Health. 2018; 6: e1077-e1086.

[59] Kudo N, Nishide R, Mizutani M, Ogawa S, Tanimura S. Association between the type of physical activity and metabolic syndrome in middle-aged and older adult residents of a semimountainous area in Japan. Environmental Health and Preventive Medicine. 2021; 26: 46.

[60] Tyrovolas S, Chalkias C, Morena M, Kalogeropoulos K, Tsakountakis N, Zeimbekis A, et al. High relative environmental humidity is associated with diabetes among elders living in Mediterranean islands. Journal of Diabetes \& Metabolic Disorders. 2014; 13: 25.

[61] Juna CF, Cho YH, Ham D, Joung H. Associations of Relative Humidity and Lifestyles with Metabolic Syndrome among the Ecuadorian Adult Population: Ecuador National Health and Nutrition Survey (ENSANUT-ECU) 2012. International Journal of Environmental Research and Public Health. 2020; 17: 9023.

[62] Togo F, Watanabe E, Park H, Shephard RJ, Aoyagi Y. Meteorology and the physical activity of the elderly: the Nakanojo Study. International Journal of Biometeorology. 2005; 50: 83-89.

[63] Chan CB, Ryan DA, Tudor-Locke C. Relationship between objective measures of physical activity and weather: a longitudinal study. The International Journal of Behavioral Nutrition and
Physical Activity. 2006; 3: 21.

[64] Pivarnik JM, Reeves MJ, Rafferty AP. Seasonal variation in adult leisure-time physical activity. Medicine and Science in Sports and Exercise. 2003; 35: 1004-1008.

[65] Uitenbroek DG. Seasonal variation in leisure time physical activity. Medicine and Science in Sports and Exercise. 1993; 25: 755-760.

[66] Hoaas H, Zanaboni P, Hjalmarsen A, Morseth B, Dinesen B, Burge AT, et al. Seasonal variations in objectively assessed physical activity among people with COPD in two Nordic countries and Australia: a cross-sectional study. International Journal of Chronic Obstructive Pulmonary Disease. 2019; 14: 12191228 .

[67] Klompstra L, Jaarsma T, Stromberg A, van der Wal MHL. Seasonal variation in physical activity in patients with heart failure. Heart and Lung. 2019; 48: 381-385.

[68] Gil MCC, Koolhaas C, Franco O, Schoufour J. Seasonality of physical activity, sedentary behavior and nighttime sleep duration in middle aged and elderly population of the Rotterdam Study. Maturitas. 2017; 103: 94

[69] Ferguson T, Curtis R, Fraysse F, Lagiseti R, Northcott C, Virgara $\mathrm{R}$, et al. Annual, seasonal, cultural and vacation patterns in sleep, sedentary behaviour and physical activity: a systematic review and meta-analysis. BMC Public Health. 2021; 21: 1384.

[70] Werneck AO, Baldew SS, Miranda JJ, Diaz Arnesto O, Stubbs B, Silva DR, et al. Physical activity and sedentary behavior patterns and sociodemographic correlates in 116,982 adults from six South American countries: the South American physical activity and sedentary behavior network (SAPASEN). The International Journal of Behavioral Nutrition and Physical Activity. 2019; 16: 68 .

[71] Plasqui G, Westerterp KR. Seasonal variation in total energy expenditure and physical activity in Dutch young adults. Obesity Research. 2004; 12: 688-694.

[72] Yasunaga A, Togo F, Watanabe E, Park H, Park S, Shephard RJ, et al. Sex, age, season, and habitual physical activity of older Japanese: the Nakanojo study. Journal of Aging and Physical Activity. 2008; 16: 3-13.

[73] Hopkins ND, Stratton G, Tinken TM, Ridgers ND, Graves LE, McWhannell N, et al. Seasonal reduction in physical activity and flow-mediated dilation in children. Medicine and Science in Sports and Exercise. 2011; 43: 232-238.

[74] Honda H, Igaki M, Komatsu M, Tanaka S. Seasonal variations on endothelium-dependent flow-mediated vasodilation in adults with type 2 diabetes and nondiabetic adults with hypertension and/or dyslipidaemia who perform regular exercise. Endocrinology, Diabetes \& Metabolism. 2021; 4: e00168.

[75] Fahrner CL, Hackney AC. Effects of endurance exercise on free testosterone concentration and the binding affinity of sex hormone binding globulin (SHBG). International Journal of Sports Medicine. 1998; 19: 12-15.

[76] Vingren JL, Kraemer WJ, Ratamess NA, Anderson JM, Volek JS, Maresh CM. Testosterone physiology in resistance exercise and training: the up-stream regulatory elements. Sports Medicine. 2010; 40: 1037-1053.

[77] Kraemer WJ, Hakkinen K, Newton RU, McCormick M, Nindl $\mathrm{BC}$, Volek JS, et al. Acute hormonal responses to heavy resistance exercise in younger and older men. European Journal of Applied Physiology and Occupational Physiology. 1998; 77: 206-211.

[78] Linnamo V, Pakarinen A, Komi PV, Kraemer WJ, Hakkinen K. Acute hormonal responses to submaximal and maximal heavy resistance and explosive exercises in men and women. Journal of Strength and Conditioning Research. 2005; 19: 566-571.

[79] Kraemer WJ, Hakkinen K, Newton RU, Nindl BC, Volek JS, McCormick M, et al. Effects of heavy-resistance training on hor- 
monal response patterns in younger vs. older men. Journal of Applied Physiology. 1999; 87: 982-992.

[80] Grandys M, Majerczak J, Duda K, Zapart-Bukowska J, Kulpa J, Zoladz JA. Endurance training of moderate intensity increases testosterone concentration in young, healthy men. International Journal of Sports Medicine. 2009; 30: 489-495.

[81] Hiruntrakul A, Nanagara R, Emasithi A, Borer KT. Effect of endurance exercise on resting testosterone levels in sedentary subjects. Central European Journal of Public Health. 2010; 18: 169-172.

[82] Bjornerem A, Straume B, Midtby M, Fonnebo V, Sundsfjord J, Svartberg J, et al. Endogenous sex hormones in relation to age, sex, lifestyle factors, and chronic diseases in a general population: the Tromso Study. Journal of Clinical Endocrinology and Metabolism. 2004; 89: 6039-6047.

[83] Fahey TD, Rolph R, Moungmee P, Nagel J, Mortara S. Serum testosterone, body composition, and strength of young adults. Medicine and Science in Sports. 1976; 8: 31-34.

[84] Pullinen T, Mero A, Huttunen P, Pakarinen A, Komi PV. Resistance exercise-induced hormonal responses in men, women, and pubescent boys. Medicine and Science in Sports and Exercise. 2002; 34: 806-813.

[85] Baker JR, Bemben MG, Anderson MA, Bemben DA. Effects of age on testosterone responses to resistance exercise and musculoskeletal variables in men. Journal of Strength and Conditioning Research. 2006; 20: 874-881.

[86] Hakkinen K, Pakarinen A, Kraemer WJ, Newton RU, Alen M. Basal concentrations and acute responses of serum hormones and strength development during heavy resistance training in middle-aged and elderly men and women. Journals of Gerontology. Series A: Biological Sciences and Medical Sciences. 2000; 55: B95-105.

[87] Hakkinen K, Pakarinen A, Newton RU, Kraemer WJ. Acute hormone responses to heavy resistance lower and upper extremity exercise in young versus old men. European Journal of Applied Physiology and Occupational Physiology. 1998; 77: 312-319.

[88] Cumming DC, Wall SR. Non-sex hormone-binding globulinbound testosterone as a marker for hyperandrogenism. Journal of Clinical Endocrinology and Metabolism. 1985; 61: 873-876.

[89] Hayashi T, Yamada T. Association of bioavailable estradiol levels and testosterone levels with serum albumin levels in elderly men. Aging Male. 2008; 11: 63-70.

[90] Ryu OH, Lee S, Yoo HJ, Choi MG. Seasonal variations in glycemic control of type 2 diabetes in Korean women. Journal of Endocrinological Investigation. 2014; 37: 575-581.

[91] Ma Y, Olendzki BC, Li W, Hafner AR, Chiriboga D, Hebert JR, et al. Seasonal variation in food intake, physical activity, and body weight in a predominantly overweight population. European Journal of Clinical Nutrition. 2006; 60: 519-528.

[92] Nadif R, Goldberg S, Gourmelen J, Ozguler A, Goldberg M, Zins $\mathrm{M}$, et al. Seasonal variations of lipid profiles in a French cohort. Atherosclerosis. 2019; 286: 181-183.

[93] Ramirez-Jimenez M, Morales-Palomo F, Ortega JF, MorenoCabanas A, Guio de Prada V, Alvarez-Jimenez L, et al. Effects of Exercise Training during Christmas on Body Weight and Cardiometabolic Health in Overweight Individuals. International Journal of Environmental Research and Public Health. 2020; 17: 4732 .

[94] Stevenson JL, Krishnan S, Stoner MA, Goktas Z, Cooper JA. Effects of exercise during the holiday season on changes in body weight, body composition and blood pressure. European Journal of Clinical Nutrition. 2013; 67: 944-949.

[95] Cano A, Ventura L, Martinez G, Cugusi L, Caria M, Deriu F, et $a l$. Analysis of sex-based differences in energy substrate utilization during moderate-intensity aerobic exercise. European Journal of Applied Physiology. 2021. (in press)

[96] Davis SN, Galassetti P, Wasserman DH, Tate D. Effects of gender on neuroendocrine and metabolic counterregulatory responses to exercise in normal man. Journal of Clinical Endocrinology and Metabolism. 2000; 85: 224-230.

[97] Bouchard DR, Beliaeff S, Dionne IJ, Brochu M. Fat mass but not fat-free mass is related to physical capacity in well-functioning older individuals: nutrition as a determinant of successful aging (NuAge)-the Quebec Longitudinal Study. Journals of Gerontology. Series A: Biological Sciences and Medical Sciences. 2007; 62: $1382-1388$.

[98] Doherty TJ. The influence of aging and sex on skeletal muscle mass and strength. Current Opinion in Clinical Nutrition and Metabolic Care. 2001; 4: 503-508.

[99] Poehlman ET, Toth MJ, Bunyard LB, Gardner AW, Donaldson $\mathrm{KE}$, Colman E, et al. Physiological predictors of increasing total and central adiposity in aging men and women. Archives of Internal Medicine. 1995; 155: 2443-2448. 